\title{
Protective efficiency of an inactivated vaccine against Streptococcus iniae in olive flounder, Paralichthys olivaceus
}

\author{
Yong-Uk Jeong, Dharaneedharan Subramanian, Yeoung-Hwan Jang, Dong-Hwi Kim, \\ So-Hyun Park, Kyung-il Park, Young-Don Lee, Moon-Soo Heo
}

Received - 22 September 2015/Accepted - 07 March 2016. Published online: 31 March 2016; OInland Fisheries Institute in Olsztyn, Poland Citation: Jeong Y.U., Subramanian D., Yeoung-Hwan J., Kim D.H., Park S.H., Park K., Lee Y.D., Heo M.S. 2016 - Protective efficiency of an inactivated vaccine against Streptococcus iniae in olive flounder, Paralichthys olivaceus - Arch. Pol. Fish. 24: 23-32

\begin{abstract}
Streptococcus iniae is a causative agent of hemorrhagic septicemia in olive flounder, Paralichthys olivaceus, in Korea, resulting in serious economic losses. As a preventive measure, M VAC INIAE (Mastuken, Japan) was prepared from the $S$. iniae F2K strain and tested against the SI-36 strain prevalent on flounder fish farms on Jeju Island, Korea. F2K had a serotype of 38 (-) and SI-36 38 (+). The vaccine recognized both serotypes. It showed a very high effective immune response against $S$. iniae; the challenge test using the $S$. iniae SI-36 strain resulted in a relative percent survival (RPS) of 85.7-87.0\% 2 weeks after vaccination and $71.0-80.0 \% 6$ months after vaccination. Field vaccination and clinical challenge tests were performed at local Jeju aquafarms with $S$. iniae SI-36. These showed significantly
\end{abstract}

Y.U. Jeong, D. Subramanian, D.H. Kim, S.H. Park, M.S. Heo [ Marine Pathogenic Microbes Lab, Department of Aquatic Biomedical Sciences, School of Marine Biomedical Sciences, Jeju National University, Jeju 690-756, South Korea

e-mail: msheo@jejunu.ac.kr

Y.-H. Jang

Jeju Special Self-Governing Province Ocean and Fisheries Research

Institute, Pyoseon-myeon, Segwipo-si, Jeju 697-914, South Korea

K. Park

Department of Aquatic Life Medicine, Kunsan National University, Kunsan 573-701, South Korea

Y.D. Lee

Marine and Environmental Institute, Jeju National University, Jeju 690-814, South Korea

Y.U. Jeong and D. Subramanian contributed equally to this work. reduced cumulative mortality when compared to the control group with RPS rates that ranged between 71-80\%. Hence, the present study suggests that this vaccine showed a significant immune response against $S$. iniae and could be applied in commercial aquafarms as a therapeutic agent against $\beta$-hemolytic streptococcosis in cultured $P$. olivaceus.

Keywords: Streptococcus iniae, $\beta$-hemolytic streptococcosis, olive flounder, inactivated vaccine, relative percent survival

\section{Introduction}

Fish streptococcal infections have been considered to be one of the major problems associated with the worldwide intensification of aquaculture since 1970 (Baya et al. 1990, Kitao 1993, Agnew and Barnes 2007). Among Streptococcus infections, Streptococcus iniae emerged as an important fish pathogen, which was first isolated from freshwater dolphins (Pier and Madin 1976). It was reported that $S$. iniae is a causative agent of hemorrhagic septicemia that accompanies meningoencephalitis, exophthalmia, and corneal opacity in farmed fish (Roberts 2001).

By 2012, Republic of Korea farmed flounder production accounted for $70 \%$ of the world's supply (Tveteras 2012). Of this, 62\% of production is derived from about 280 inland aquafarms. In Jeju

(c) Copyright by Stanisław Sakowicz Inland Fisheries Institute in Olsztyn.

(C) 2016 Author(s). This is an open access article licensed under the Creative Commons Attribution-NonCommercial-NoDerivs License (http://creativecommons.org/licenses/by-nc-nd/3.0/). 
Island alone, 24,575 $\mathrm{mt}$ of flounder were produced at farms covering a total of 100 ha of water. This has become one of the most important industries on this island (KOSIS 2012). Intensification of culture is probably the cause of the enhanced propagation of bacterial, viral, and/or parasitic pathogens. In May 2005, flounder cultured in cage-culture systems on Jeju Island experienced high mortality rates with bilateral exopthalmic eyes and rotten gills (Baeck et al. 2006, Jang et al. 2013).

Previous reports on the bacterial diseases of cultured flounder that occurred in this area were associated with streptococcosis (Jung et al. 2004), namely Streptococcos iniae and S. parauberis. Among them, $S$. iniae is reported to be a major fish pathogen in many regions of the world. The plasminogen binding property of the pathogenic $S$. iniae strain could suggest its virulence level, which could contribute to tissue invasion and overall pathogenicity (Boyle and Lottenberg 1997). Hence, they are also zoonotic with infection in humans associated with handling and preparing infected fish (Weinstein et al. 1997). According to Jeong et al. (2006) the infection rate of $S$. iniae in Jeju Island was 46\% throughout 2003, and in 2005 it occurred throughout the year with high prevalence in the summer (Nguyen et al. 2002). In particular, it was known that market size flounder over $30 \mathrm{~cm}$ in length were more susceptible to $S$. iniae, resulting in serious economic losses (Jeong et al. 2006). A few studies have reported on a second serotype of $S$. iniae isolated from diseased fish from Israel and the USA (Bachrach et al. 2001, Barnes et al. 2003a).

In general, the increased use of antibiotics in aquaculture has increased the resistance of $S$. iniae and prompted demands for an effective vaccine (Stoffregen et al. 1996, Shoemaker et al. 2001). Currently, several formalin-killed vaccines against $\beta$-hemolytic $S$. iniae strains are used in Korea (Cho et al. 2006, Moon et al. 2007, Shin et al. 2007). In particular, the $\beta$-hemolytic vaccine M VAC ININAE (Mastuken, Japan), which was developed with the $S$. iniae - F2K strain, is commercially available in Korea and Japan. The purpose of this study was to examine the chronic effect of serotypes of $S$. iniae in aquafarms located on Jeju, Korea in two clinical trials and to evaluate the efficacy, safety, and clinical administration of the $S$. iniae vaccine.

\section{Material and methods}

\section{Bacterial strains and their characterization}

The bacterial strains were isolated from pure cultures of infected olive flounder kidney and spleen, and they were also obtained from the Korean Collection for Type Cultures (KCTC). The strain F2K, used in the development of vaccine for $S$. iniae, was purchased from Mastuken, Japan. All bacterial strains were grown on Brain-Heart Infusion (BHI) agar (Difco, Grand Island, NY, USA) supplemented with $1.5 \% \mathrm{NaCl}$ and $5 \%$ sheep blood (KOMED, Seoul, Korea) for $24-48 \mathrm{~h}$ at $25^{\circ} \mathrm{C}$. Glycerol stocks of each isolated strain were prepared with $20 \%$ (v/v) glycerol in $\mathrm{BHI}$ broth $(\mathrm{BD})$ and stored at $-80^{\circ} \mathrm{C}$. Isolates were cultured overnight at $20^{\circ} \mathrm{C}$ in BHI broth and Gram staining and motility tests were performed. General cell morphology was studied with phase contrast and scanning electron microscopy (SEM) according to standard procedures. Phenotypic characterization was carried out on all strains with an API 20E kit (BioMérieux) at $25^{\circ} \mathrm{C}$, and the results were analyzed at 24 and $48 \mathrm{~h}$. VITEC (BioMerieux) cards were also inoculated and allowed to incubate overnight for automated reading of reactions. Hemolysis tests were conducted in pure isolates using a 5\% sheep blood agar plate (KOMED).

\section{Vaccine preparation}

The S. iniae vaccine was prepared with $10 \%$ neutrally-buffered formalin in a $0.3 \%$ solution on F2K strain cultures $\left(1 \times 10^{7} \mathrm{CFU} 100 \mathrm{ml}^{-1}\right)$, and this was used as the inactivated $S$. iniae vaccine according to the manufacturer's instructions (M VAC INIAE, Mastuken, Japan). 


\section{Preparation of rabbit antisera}

Rabbit was immunized with intravenous injection of M VAC INIAE prepared from the $S$. iniae F2K strain, twice weekly in consecutive doses of $0.2,0.4,0.8$, and $1.0 \mathrm{ml}$. One week after the last injection, the rabbit was bled from the ear vein. Two weeks later, this immunization procedure was repeated, now with 1.0 $\mathrm{ml}$ doses throughout. The antisera were stored at $-20^{\circ} \mathrm{C}$ until use.

\section{Slide agglutination test for $S$. iniae}

The test was performed by mixing a small amount of each bacterial colony with several drops of 38 (-) or $38(+)$ antiserum of the $S$. iniae $(\mathrm{F} 2 \mathrm{~K})$ developed in rabbits.

\section{Fish}

About 500 healthy olive flounder (mean weight of $65.5 \pm 0.13 \mathrm{~g}$ ) were obtained from commercial fish farms on Jeju Island. The fish were habituated for two weeks in a 1.5-ton tank equipped with an ultraviolet sterilizer on a closed circulatory filter, and water temperature was maintained at $22 \pm 1^{\circ} \mathrm{C}$ prior to the experiments. Throughout the immunogenicity and challenge experiments, the fish were held under standard culture conditions and fed twice a day with a commercial pelleted diet. The fish were confirmed to be negative for $S$. iniae infection by culturing fish tissue in BHI agar (BD, USA).

\section{Immunogenicity test}

For the immunogenicity test, 500 olive flounder were selected that had not been previously exposed to antibiotics and with no traces of the $S$. iniae antibody. For vaccine inoculation, all fish were anesthetized by immersion in a tank containing $150 \mathrm{mg} \mathrm{l}^{-1}$ of tricaine methanesulfonate for $15 \mathrm{~min}$ and divided into two groups ( $\mathrm{n}=125$, in duplicate) - the control and vaccinated groups - and each group of fish received either $100 \mu \mathrm{l}$ of phosphate-buffered saline (PBS: $0.2 \mathrm{M}$ monobasic phosphate, $0.2 \mathrm{M}$ dibasic phosphate,
$0.11 \mathrm{M}$ sodium chloride, $\mathrm{pH}$ 7.4) or the vaccine intraperitoneally. To test antibody formation, serum was extracted from the tail vein of 10 fish from each PBS and vaccine-treated group starting 2 weeks after vaccination and up to 9 weeks after vaccination. The serum obtained was used for the agglutination assay (Yildirim et al. 2003). Briefly, $50 \mu \mathrm{L}$ of serum was serially diluted in a 96-well microplate with $50 \mu \mathrm{L}$ of PBS. After this, $50 \mu \mathrm{L}$ of vaccine was added to each well as an antigen and incubated in a humidified chamber at $25^{\circ} \mathrm{C}$ for $24 \mathrm{~h}$. Agglutination titers were expressed as $\log 2(\mathrm{x}+1)$ of the reciprocal of the highest serum dilution showing visible agglutination as compared to the positive control.

The last well, in which there was only $50 \mathrm{~mL}$ PBS buffer, was the negative control.

\section{Challenge experiment}

For the challenge test, after two weeks of vaccination, forty fish from each vaccinated and control fish groups were injected intraperitoneally with $100 \mu \mathrm{l}$ of the challenge strain $S$. iniae-SI-36, $\left(1 \times 10^{7} \mathrm{CFU}\right.$ $\mathrm{ml}^{-1}, \mathrm{LD}_{70}$ ) and PBS, respectively. Mortalities were recorded for 2 weeks, and any clinical symptoms in survivors were noted. The cause of death and pathological symptoms were confirmed by re-isolating bacteria from kidney samples of freshly dead fish or survivors. Cumulative mortality was registered and relative percent survival (RPS) was calculated according to the formula: RPS $(\%)=[1-($ cumulative mortality of the vaccine-treated group/cumulative mortality of the PBS-treated group) $] \times 100$. The vaccine was found to be efficient if the relative percent survival (RPS) rate of the vaccine-treated group was more than $60 \%$ when compared to that of PBS-treated group (Amend 1981).

\section{First clinical trial of the vaccine at aquafarms}

Vaccine efficacy was tested at five aquafarms located on the northeast (aquafarm A) and southeast (aquafarms B, C, D and E) coasts of Jeju Island (Fig. 
Table 1

Phenotypic characteristics of Streptococcus spp. KCTC: Korean Collection for Type Cultures

\begin{tabular}{|c|c|c|c|c|c|}
\hline \multirow{2}{*}{$\begin{array}{l}\text { Species } \\
\text { Strain }\end{array}$} & \multicolumn{3}{|l|}{ S. iniae } & \multicolumn{2}{|l|}{ S. parauberis } \\
\hline & F2K & SI-36 & КСТC-3657 & SP-5 & KCTC-3651 \\
\hline Host & Olive flounder & Olive flounder & Dolphin & Olive flounder & Bovine mastitis \\
\hline Gram stain & cocci & cocci & cocci & cocci & cocci \\
\hline Growth at aerobic condition & + & + & + & + & + \\
\hline $5 \% \mathrm{CO}_{2}$ & + & + & + & + & + \\
\hline OF-test & + & + & + & + & + \\
\hline Growth at $10^{\circ} \mathrm{C}$ & - & - & - & - & - \\
\hline $45^{\circ} \mathrm{C}$ & - & - & - & - & - \\
\hline pH 9.6 & - & - & - & - & - \\
\hline Growth in $6.5 \% \mathrm{NaCl}$ & - & - & - & - & - \\
\hline $40 \%$ Bile solubility test & - & - & - & - & - \\
\hline $0.25 \%$ Optochin sensitivity test & + & + & + & + & + \\
\hline Hemolysis (Goat RBC) & $\beta$ & $\beta$ & $\beta$ & $\alpha$ & $\gamma$ \\
\hline Hydrolysis of arginine & - & + & + & + & + \\
\hline Hydrolysis of hippurate & - & - & - & + & + \\
\hline Hydrolysis of esculin & + & + & + & - & - \\
\hline Acid production from Inulin & - & - & - & - & - \\
\hline Lactose & - & - & - & + & + \\
\hline Mannitol & + & + & + & + & + \\
\hline Raffinose & - & - & - & - & - \\
\hline Ribose & + & + & + & - & - \\
\hline Salicin & + & + & + & + & + \\
\hline Sorbitol & - & - & - & - & - \\
\hline Trehalose & + & + & + & + & + \\
\hline Alkaline phosphatase & - & + & + & + & + \\
\hline$\beta$-Galactosidase & - & - & - & + & + \\
\hline$\alpha$-Glucoronidase & - & - & - & - & - \\
\hline$\alpha$-Galactosidase & - & - & - & - & - \\
\hline Pyrroidonyl arylamidase & - & + & + & + & + \\
\hline VP-test & - & - & - & + & + \\
\hline
\end{tabular}




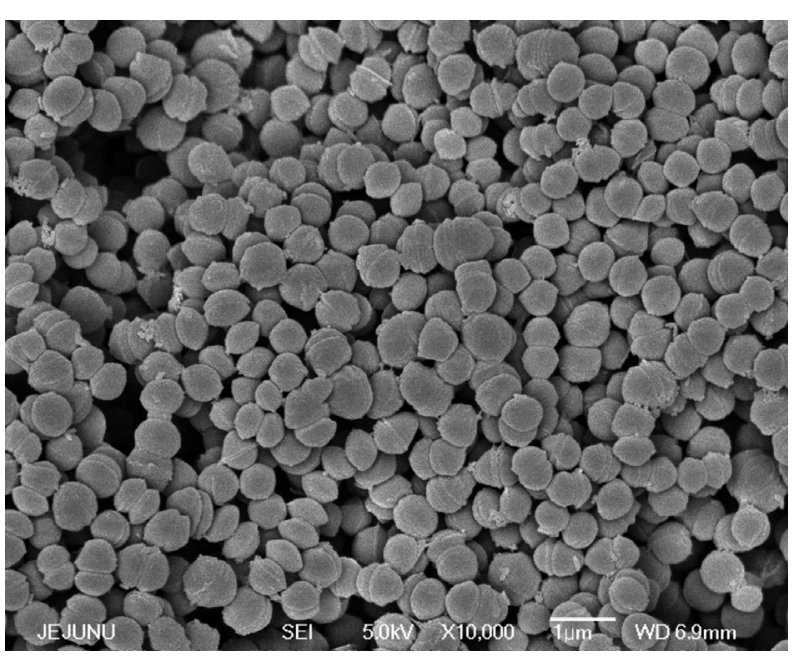

Figure 1. Geographical distribution of flounder farms where vaccine clinical tests were performed on Jeju Island, South Korea.

1). All farms have been practicing flounder culture for more than a decade. At each of the aquafarms, four culture ponds (two control and two vaccinated fish groups) with numbers of fish ranging from 5,700 to 10,000 and with average body weights of about $150.1 \pm 0.2 \mathrm{~g}$ were selected. All fish in the vaccinated ponds were injected with vaccine as previously mentioned. Growth and the natural infection pattern of $S$. iniae were monitored for $20 \pm 2$ weeks at all the aquafarms. Necropsies were performed on all of the dead fish that exhibited $\beta$-hemolytic streptococcosis symptoms to determine whether they were infected with Streptococcus. Multiplex PCR diagnosis for $S$. iniae was also carried out according to Mata et al. (2004).

\section{Second clinical trial of the vaccine at aquafarms}

A second clinical trial was performed to assess the chronic efficiency of the vaccine six months after vaccination. For this, fish from aquafarms $\mathrm{B}$ and $\mathrm{C}$ were transported to the Marine Research Institute of Jeju National University, and acclimated for 4 weeks in a 1.5-ton FRP water tank equipped with an ultraviolet sterilizer in a closed circulatory filter. At the beginning of the experiment the average fish weight ranged from 410 to $700 \mathrm{~g}$. In the challenge test, 100 $\mu \mathrm{l}\left(1 \times 10^{7} \mathrm{CFU} \mathrm{ml}^{-1}\right.$ LD $\left._{70}\right)$ of SI-36 strain was injected intraperitoneally and cumulative mortality was recorded for the following 2 weeks. Vaccine efficiency was calculated by obtaining the RPS rate of both the control and vaccinated challenged fish groups. All dead fish were examined for the presence of S. iniae and S. parauberis using the multiplex PCR method.

\section{Statistical data analysis}

All data were analyzed using one-way ANOVA to test the effects of the vaccine among vaccinated and non-treated groups. A $t$-test was performed using SAS statistical software (SAS Institute, Cary, NC, USA).

\section{Results and discussion}

The isolates were strictly anaerobic, Gram-positive, sphere-shaped bacteria (Fig. 2) that grew at $37^{\circ} \mathrm{C}$. The phenotypic characteristics of Streptococcus spp., including strains obtained from the Korean Collection for Type Cultures and the isolates from diseased fish, are listed in Table 1. Among the different strains, the F2K strain used in the production of the vaccine against $S$. iniae was compared to known KCTC-3657 and SI-36 (wild-type) strains. According to the comparison, the F2K strain showed a high similarity to the phenotypic characteristics of $S$. iniae and was distinguishable from $S$. parauberis. However, the F2K strain showed negative reactions to arginine dihydrolase, alkaline phosphatase, and pyrroidonyl arylamidase, unlike the KCTC-3657 and SI-36 strains. Therefore, the F2K strain demonstrated a different phenotypic polymorphism than that of general S. iniae.

Recent studies proposed that bacterial success is influenced by serotypic variation (Klesius et al. 2000, Agnewa and Barnes 2007). In the present study, serological identification using $S$. iniae with antisera $38(-)$ and $38(+)$ was performed on $S$. parauberis strains (KCTC-3651 and SP-5) and S. iniae strains 
Table 2

Serological characteristics of $S$. iniae and S. parauberis

\begin{tabular}{lllllll}
\hline & \multicolumn{3}{l}{ S. iniae strains } & & & S. parauberis \\
\cline { 2 - 6 } Anti-sera & F2K & SI-4 & Sl-36 & KCTC-3657 & SP-5 & KCTC-3651 \\
\hline \hline Anti-sera to 38(-) type & + & + & + & + & - & - \\
Anti-sera to 38(+) type & - & + & + & + & - & No type \\
Serotype & $38(-)$ & $38(+)$ & $38(+)$ & $38(+)$ & No type \\
\hline \hline
\end{tabular}

Table 3

Cumulative mortality and relative percentage survival (RPS) rate of $P$. olivaceus for 2 weeks post-vaccination with the M VAC INIAE vaccine and challenged with $S$. iniae

\begin{tabular}{lllll}
\hline \hline $\begin{array}{l}\text { Test } \\
\text { group }\end{array}$ & $\begin{array}{l}\text { Treatment } \\
\text { group }\end{array}$ & $\begin{array}{l}\text { No. of fish } \\
\text { (dead/ } \\
\text { challenged) }\end{array}$ & $\begin{array}{l}\text { Cumulative } \\
\text { mortality }(\%)\end{array}$ & $\begin{array}{l}\text { RPS } \\
(\%)\end{array}$ \\
\hline \hline 1 & PBS & $23 / 30$ & 76.7 & 87.0 \\
& Vaccinated & $3 / 30$ & 10.0 & \\
2 & PBS & $21 / 30$ & 70.0 & 85.7 \\
& Vaccinated & $3 / 30$ & 10.0 & \\
\hline \hline
\end{tabular}

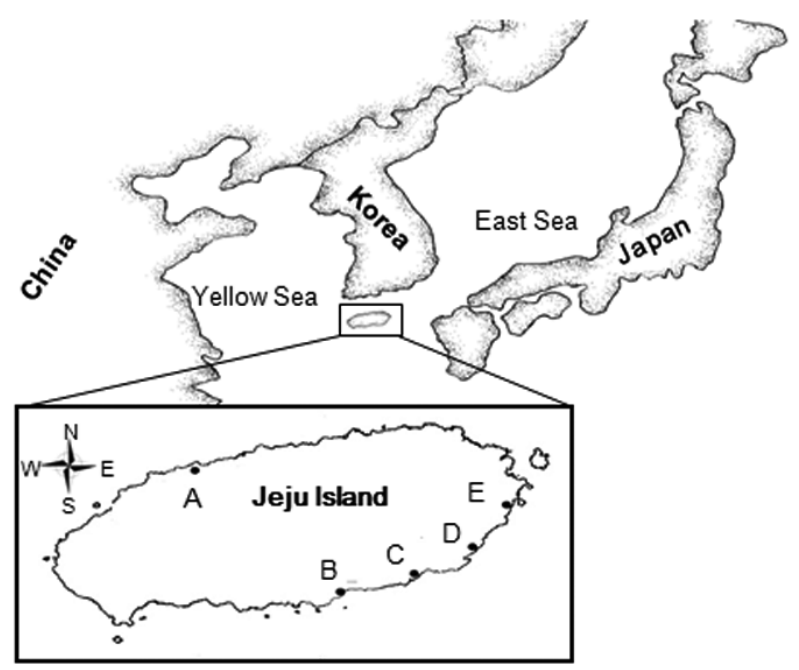

Figure 2. Scanning electron micrograph (SEM) of S. iniae strains isolated from infected olive flounder on Jeju Island, South Korea.

(F2K, KCTC-3657, SI-4 and SI-36). The results indicated that no coagulated reactions were found with any $S$. parauberis strains, while the $S$. iniae strains, such as KCTC-3657, SI-4, and SI-36, showed signs of agglutination in all $38(-)$ and $38(+)$ antisera, and were assigned to serotype $38(+)$ (Table 2$)$. On the other hand, strain F2K showed signs of agglutination only with the 38 (-) type antiserum; hence, it was assigned to serotype $38(-)$. These results support the existence of two serotypes in $S$. iniae; the serological characters of the F2K strain indicate that it retained both $38(-)$ and $38(+)$-type-specific antigens. The phenotypic polymorphism results showed that the F2K strain had many similarities to $S$. iniae serotype II, which has extremely high pathogenicity with negative arginine dehydrolase activity (Bachrach et al. 2001, Barnes et al. 2003a, Zlotkin et al. 2003). According to these studies, serotype I responded to both serotypes I and II antisera, but serotype II showed agglutination activity only with serotype II antiserum. An experiment on the removal of cell-surface protein components suggested that the antigenic determinant could only exist in serotype II, which may not be a capsule component, and, therefore, it could be a cell-surface protein (Barnes et al. 2003b). Accordingly, the high similarity of biochemical tests between the $\mathrm{F} 2 \mathrm{~K}$ and $\mathrm{AD}$ type strains (Barnes et al. 2003a) suggests that the F2K strain could be the same serotype as serotype II since it retains both serotype I and II antigens. Therefore, F2K is an important strain to consider when making a vaccine because the strain has a cross-reactivity to both serotypes: the $38(-)$ and $38(+)$ strains.

In the immunogenicity test against $S$. iniae (F2K) the agglutination titer rapidly increased from $2^{2.7}$ to $2^{4}$ from week 2 to 4 two weeks after the vaccination 
Table 4

Number of fish and cumulative mortality rates for each clinical test group reared 6 months at 5 flounder aquafarms on Jeju Island, Korea

\begin{tabular}{|c|c|c|c|c|c|c|c|c|c|}
\hline \multirow[b]{2}{*}{ Aquafarm } & \multirow[b]{2}{*}{ Group } & \multirow[b]{2}{*}{$\begin{array}{l}\text { No. of } \\
\text { fish }\end{array}$} & \multirow[b]{2}{*}{$\begin{array}{l}\text { Average } \\
\text { body } \\
\text { weight (g) }\end{array}$} & \multicolumn{4}{|c|}{ No. of dead fish caused by* } & \multirow[b]{2}{*}{$\begin{array}{l}\text { Cumulated } \\
\text { mortality (\%) }\end{array}$} & \multirow[b]{2}{*}{$\begin{array}{l}\text { Total } \\
\text { dead fish }\end{array}$} \\
\hline & & & & S. iniae & S. parauberis & $\begin{array}{l}\text { Other } \\
\text { disease** }\end{array}$ & $\begin{array}{l}\text { Total \# } \\
\text { of fish } \\
\text { examined }\end{array}$ & & \\
\hline \multirow[t]{2}{*}{ A } & Control & 6,400 & 165 & 0 & 3 & 26 & 55 & 7.6 & 448 \\
\hline & Vaccinated & 6,100 & 165 & 0 & 7 & 38 & 61 & 5.7 & 547 \\
\hline \multirow[t]{2}{*}{ B } & Control & 3,338 & 176 & 0 & 4 & 40 & 53 & 13.6 & 465 \\
\hline & Vaccinated & 3,289 & 165 & 3 & 2 & 64 & 87 & 16.6 & 348 \\
\hline \multirow[t]{2}{*}{$\mathrm{C}$} & Control & 10,000 & 165 & 1 & 16 & 137 & 177 & 6.2 & 502 \\
\hline & Vaccinated & 9,229 & 165 & 4 & 13 & 139 & 175 & 6.2 & 505 \\
\hline \multirow[t]{2}{*}{$\mathrm{D}$} & Control & 9,000 & 125 & 0 & 20 & 59 & 116 & 12.5 & 1,128 \\
\hline & Vaccinated & 8,663 & 125 & 0 & 7 & 73 & 118 & 27.5 & 2,371 \\
\hline \multirow[t]{2}{*}{$\mathrm{E}$} & Control & 5,669 & 125 & 0 & 156 & 28 & 303 & 36.8 & 2,095 \\
\hline & Vaccinated & 5,700 & 125 & 0 & 143 & 52 & 297 & 38.4 & 2,187 \\
\hline
\end{tabular}

*Examination was carried out on $\leq 10$ dead fish randomly selected on each day.

** Other diseases: Edwardsiellosis, Vibriosis, Flexibacteriosis, Ichtyobodiosis, Scuticociliatosis.

treatment, reaching a maximum of $2^{4.6}$ at week 8 , and then declining to $2^{4.5}$ at week 9 post-vaccination (Fig. 3). These results indicate that the immune system of the olive flounder generate the specific antibody and has positive immunogenicity against $S$. iniae (F2K).

The practical protection effect was determined through challenge tests, which were performed twice 2 weeks after vaccination. Fish that had been artificially infected with S-36 started to die on the fourth day after injection and presented typical signs of Streptococcus infection, such as exophthalmia (pop-eye), hemorrhaging in the eye, ascitic fluid in the intra-peritoneal cavity, and a darkened surface. Furthermore, the cumulative mortality rates of PBS-treated groups 1 and 2 were 76.7 and $70.0 \%$, respectively, while the cumulative mortality rate of vaccine-treated groups 1 and 2 was only $10.0 \%$ (Table 3). Mortality of fish in the control groups initiated from $4-5 \%$ at day 4 then sharply increased to about
$60 \%$ on day 7 , while in the vaccine treated groups it was less than $10 \%$ during the same period (Fig. 4). The efficiencies of the vaccine (RPS) in groups 1 and 2 were 87.0 and $85.7 \%$, respectively (Table 3 ). The protection results suggest that single administration of the vaccine showed similar efficacies to the results Moon et al. (2007) and Cho et al. (2006) reported regarding testing the efficacies of vaccines against $S$. iniae. Culture re-isolation of the challenge strain confirmed that the fish were infected by the challenged strain and not by other pathogenic fish bacteria (data not shown). Therefore, the vaccine challenge test results indicated that fish can develop specific antibodies against $S$. iniae (SI-36) when the vaccine was administered to $P$. olivaceus.

The results of clinical trials carried out in five flounder aquafarms on Jeju Island using the $S$. iniae vaccine are illustrated in Table 4 . The average weights of the fish in each clinical trial ranged from 125 to $176 \mathrm{~g}$, and the evaluation group had 


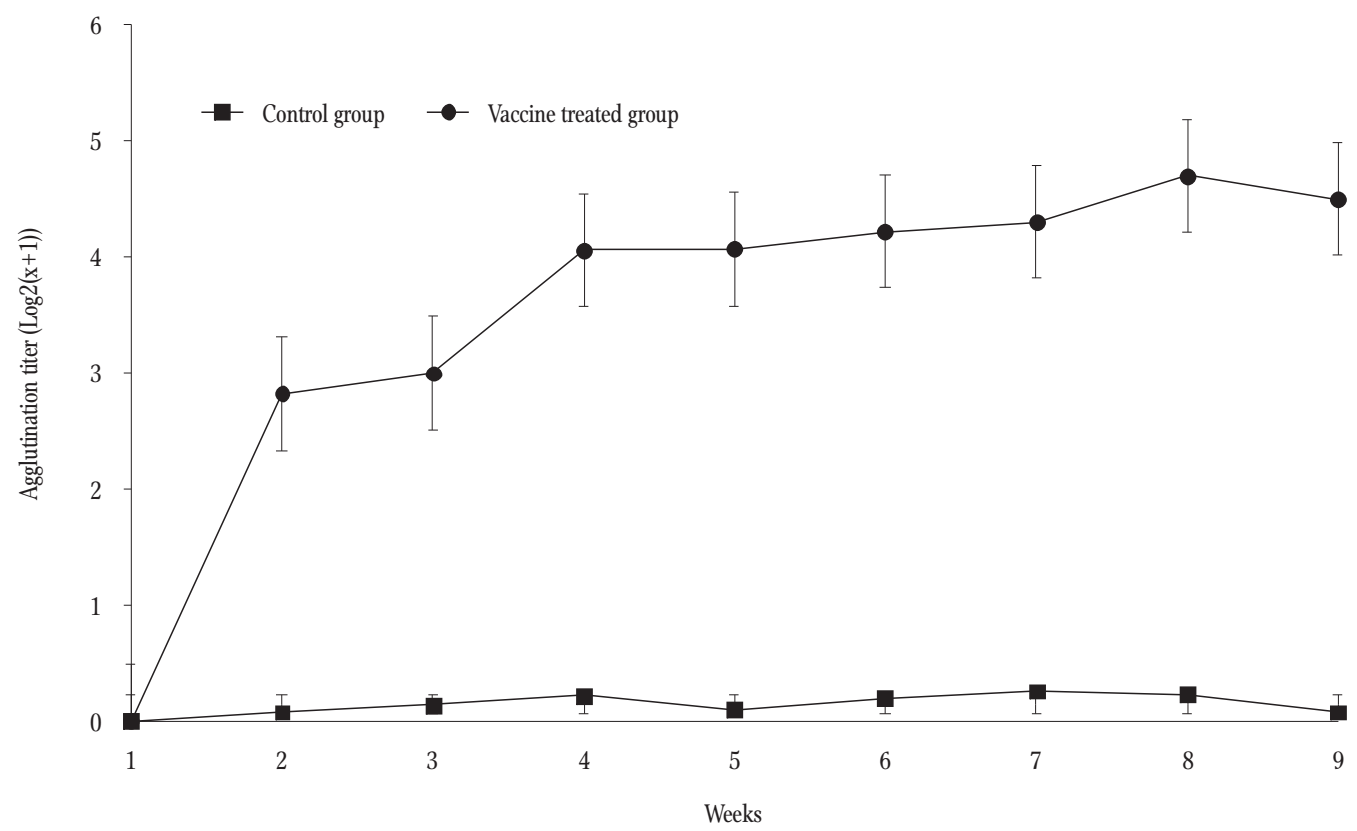

Figure 3. Serum antibody response in agglutination titers against $S$. iniae from olive flounder (P. olivaceus) injected with the M VAC INIAE vaccine. Control fish were treated with physiological saline. Closed squares, control group; closed circle, vaccine-treated group.

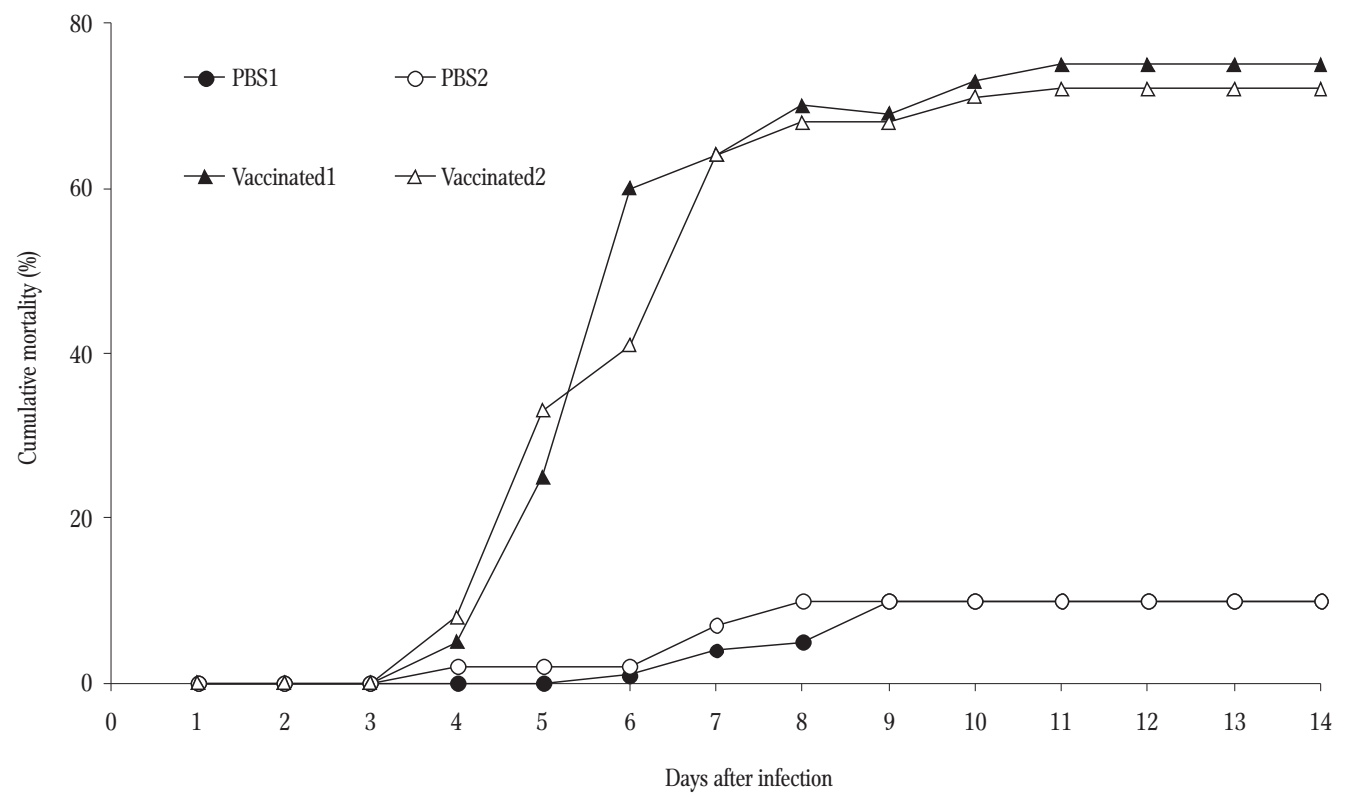

Figure 4. Changes in the cumulative mortality rate of olive flounder ( $P$. olivaceus) 2 weeks post-vaccination with the M VAC INIAE vaccine, challenged with $S$. iniae. PBS 1 - phosphate-buffered saline test group 1, PBS 2 - phosphate-buffered saline test group 2.

approximately 5,600 to 10,000 fish. However, no effect of the vaccine was observed at any of the aquafarms. At each aquafarm, cumulative mortality ranged from 5 to $38 \%$ depending on the aquafarm and with no difference between the vaccinated and control groups. It is believed that the main reason the vaccine had no effect is attributed to the very low occurrence of $S$. iniae during the experiment. Indeed, the multiplex PCR assay designed to detect $S$. iniae and $S$. parauberis showed that $S$. iniae were diagnosed in only 3 and 4 vaccinated fish at aquafarms B and $\mathrm{C}$, respectively. In the control group, only 1 dead fish showed $S$. iniae infection at aquafarm C. In contrast to $S$. iniae infection, high prevalence of $S$. 
Table 5

Cumulative mortality and relative percent survival (RPS) of olive flounder (P. olivaceus) challenge with S. iniae (SI-36) 6 months after vaccination at aquafarms $\mathrm{B}$ and $\mathrm{C}$

\begin{tabular}{|c|c|c|c|c|c|}
\hline Aquafarm & Treatment group & Challenge period & No. of fish (dead/challenged) & Cumulative mortality (\%) & RPS (\%) \\
\hline \multirow[t]{2}{*}{ B } & Control & 2 weeks & $75 / 100$ & 75.0 & 80.0 \\
\hline & Vaccinated & & $15 / 100$ & 15.0 & \\
\hline \multirow[t]{2}{*}{$\mathrm{C}$} & Control & 2 weeks & $82 / 125$ & 66.0 & 71.00 \\
\hline & Vaccinated & & $20 / 104$ & 19.2 & \\
\hline
\end{tabular}

parauberis was noted at all aquafarms during the experiment, suggesting that the vaccine does not have a protective effect against $S$. parauberis. Therefore, the efficacy of the vaccine M VAC INIAE was not consistent at all aquafarms as high levels of other bacterial and parasitic diseases such as edwardsiellosis, vibriosis, flexibacteriosis, and scuticociliatosis were also causative agents of dead fish at the aquafarms (Table 4).

Due to low prevalence of $S$. iniae at the aquafarms, more than 200 fish immunized or non-treated at aquafarms B and C, respectively, were challenged with $S$. iniae (SI-36) 6 months after vaccination and monitored for mortality rates and RPS for a 2-week period (Table 5). During the experiment, the non-treated fish group started to die on the sixth day after injection at both aquafarms, showing typical symptoms of streptococcosis, with exophthalmia, hemorrhaging in the eye, ascitic fluid in the intraperitoneal cavity, and a darkened surface. The cumulative mortalities of the vaccinated and non-treated groups at aquafarm B were 15.0 and 75.0\%, respectively. Similarly, at aquafarm C cumulative mortality rates in the test and control groups were 19.2 and $66.0 \%$, respectively. RPS rates were $80 \%$ at aquafarm $\mathrm{B}$ and $71 \%$ at aquafarm C. Re-isolating the challenge strain in dead fish confirmed that the vaccine could be a homogeneous strain. More than $80 \%$ of dead fish showed typical symptoms of streptococcosis in the control group, while vaccinated fish exhibited only a $20 \%$ mortality rate caused by disease in each aquarium (data not shown).

Hence, the results of this study permit concluding that the vaccine M VAC INIAE has a protective effect on the wild type $S$. iniae (SI-36) in olive flounders on Jeju, and immunity against $S$. iniae lasted for at least 6 months. However, the application of the vaccine to control $S$. iniae in the olive flounder on Jeju should be done based on the prevalence of the disease.

Acknowledgments. The authors gratefully acknowledge a National Research Foundation of Korea (NRF) grant funded by the government of Korea (MEST) (No. 2013RIAIA403011090). The authors are also grateful to Yuhan Corporation, Korea for providing the vaccine and financial support.

Author contributions. Y-U.J. designed the experiment and methods; all of the authors did all the experiment procedures; D.S. statistically analyzed the data, prepared the manuscript, and conducted the literature review; Y-D. L and M-S. H reviewed the article.

\section{References}

Amend D.F. 1981 - Potency testing of fish vaccines - Dev. Biol. Stand. 49: 447-454.

Agnew W., Barnes A.C. 2007 - Streptococcus iniae: an aquatic pathogen of global veterinary significance and a challenging candidate for reliable vaccination - Vet. Microbiol. 122: 1-15. 
Bachrach G., Zlotkin A., Hurvitz D., Evans L., Elder A.E. 2001 - Recovery of Streptococcus iniae from diseased fish previously vaccinated with a streptococcus vaccine - Appl. Environ. Microbiol. 67: 3756-3758.

Baeck G.W., Kim J.H., Gomez D.K., Park S.C. 2006 - Isolation and characterization of Streptococcus sp. from diseased flounder (Paralichthys olivaceus) in Jeju Island - J. Vet. Sci. 7: 53-58.

Barnes A.C., Young F.M., Horne M.T., Ellis A.E. 2003a Streptococcus iniae; serological differences, presence of capsule and resistance to immune serum killing - Dis. Aquat. Organ. 53: 241-247.

Barnes A.C., Horne M.T., Ellis A.E. 2003b - Streptococcus iniae expresses a cell surface non-immune trout immunoglobulin-binding factor when grown in normal trout serum - Fish Shellfish Immunol. 15: 425-431.

Baya A.M., Lupiani B., Hetrick F.M., Roberson B.S., Lukakovic R., May E., Poukish C. 1990 - Association of Streptococcus sp. with fish mortalities in the Chesapeake Bay and its tributaries - J. Fish Dis. 13: 251-253.

Boyle M.D.P., Lottenberg R. 1997 - Plasminogen activation by invasive human pathogens - Thromb. Haemost. 77: 1-10.

Cho M. Y., Lee J. S., Lee D. C.,. Choi H. J, Kim J. W. 2006 Immune response of olive flounder, Paralichthys olivaceus against $\beta$-hemolytic Streptococcus iniae formalin-killed cells - J. Fish Pathol. 19: 73-82.

Jang Y.H., Dharaneedharan S., Kang B.J., Heo M.S. 2013 Isolation and infectious temperature optimization of genetically similar VHSV isolates in farmed olive flounder, Paralichthys olivaceus - Isr. J. Aquac.-Bamidgeh, 66: 949-955.

Jeong Y.U., Kang C.Y., Kim M.J., Heo M.S., Oh D.C., Kang B.J. 2006 - Characterization of streptococcosis occurrence and molecular identification of the pathogens of cultured flounder in Jeju Island - Korean J. Microbiol. 42: 199-204.

Jung Y.U., Kang B.J., Park G.T., Heo M.S. 2004 - Use of 16S-23S rRNA intergenic spacer region for identification in the fish pathogenic Streptococcus iniae - J. Fish Pathol. 17: 91-98.

Kitao T. 1993 - Streptococcal infections - In: Bacterial disease of fish (Eds) V. Inglis, R.J. Roberts, N.R. Bromage, Blackwell, Oxford: 169-210.

Klesius P.H., Shoemaker C.A., Evans J.J. 2000 - Efficacy of single and combined Streptococcus iniae isolate vaccine administered by intraperitoneal and intramuscular routes in tilapia (Oreochromis niloticus) - Aquaculture, 188: 237-246.
KOSIS 2012 - Korean Statistical Information Service: Status of fish culture in Fishery in Agriculture, Forestry and Fishery - Available at http://kosis.kr.

Mata A.I., Gibello A., Casamayor A., Blanco M.M., Domínguez L., Fernández-Garayzábal J.F. 2004 - Multiplex PCR assay for detection of bacterial pathogens associated with warm-water streptococcosis in fish - Appl. Environ. Microbiol. 70: 3183-3187.

Moon J.S., Hwan J., Ji Yeon Kim, Seong J.J., Min J.K., Seong W.S. 2007 - Evaluation on efficacy of $\beta$-hemolytic Streptococcus iniae vaccine on olive flounder, Paralichthys olivaceus - Korean J. Vet. Res. 47: 291-298.

Nguyen H.T., Kanai K., Yoshikoshi K. 2002 - Ecological investigation of Streptococcus iniae in cultured Japanese flounder (Paralichthys olivaceus) using selective isolation procedures - Aquaculture, 205: 7-17.

Pier G.B., Madin S.H. 1976 - Streptococcus iniae sp. nov., a beta-hemolytic streptococcus isolated from and Amazon freshwater dolphin, Inia geoffrensis - Int. J. Syst. Bacteriol. 26: 545-553.

Roberts R.J. 2001 - Fish pathology - W.B. Saunders Press, London, p. 324.

Shin G.W., Palaksha K.J., Kim Y.R., Nho S.W., Kim S., Heo G.J., Park S.C., Jung T.S. 2007 - Application of immunoproteomics in developing Streptococcus iniae vaccine for olive flounder (Paralichthys olivaceus) - J. Chromatogr. B. 849: 315-322.

Shoemaker C.A., Klesius P.H., Evans J.J. 2001 - Prevalence of Streptococcus iniae in tilapia, hybrid striped bass, and channel catfish on commercial fish farms in the United States - Am. J. Vet. Res. 62: 174-177.

Stoffregen D., Backman S., Perham R., Bowser P., Babish J. 1996 - Initial disease report of Streptococcus iniae infection in hybrid striped (sunshin) bass and successful therapeutic intervention with the fluoroquinolone antibacterial enrofloxacin - J. World Aquacult. Soc. 27: 420-434.

Tveteras R. 2012 - Global fish production and trends in 2012-2013 - Vietfish Int. 10: 51.

Weinstein M.R., Litt M., Kertesz D.A., Wyper P., Rose D., Coulter M., McGeer A., Facklam R., Ostach C., Willey B.M.,. Borczyk A, Low D.E 1997 - Invasive infections due to a fish pathogen Streptococcus iniae - N. Engl. J. Med. 337: 589-594.

Yildirim M., Lim C., Wan P.J., Klesius P.H. 2003 - Growth performance and immune response of channel catfish (Ictalurus puctatus) fed diets containing graded levels of gossypol-acetic acid - Aquaculture, 219: 751-768.

Zlotkin A., Chilmonczk S., Eyngor M., Hurvitz A., Ghittino C., Eldar A. 2003 - Trojan horse effect: phagocyte-mediated Streptococcus iniae infection of fish - Infect. Immun. 71: 2318-2325. 